\section{O cumprimento da Emenda Constitucional no. 29 no Brasil}

\author{
Compliance with Constitutional Amendment 29 \\ in Brazil
}

\author{
1 Programa de Pós-gradu- \\ ação em Saúde Pública, \\ Universidade Federal \\ de Santa Catarina, \\ Florianópolis, Brasil. \\ Correspondência \\ M. G. R. Campelli \\ Programa de Pós-graduação \\ em Saúde Pública, \\ Universidade Federal de \\ Santa Catarina. \\ Av. Rubens de Arruda \\ Ramos 1082, apto. 501, \\ Florianópolis, SC \\ 88015-700, Brasil. \\ magalicampelli@yahoo.com.br
}

\begin{abstract}
Constitutional Amendment 29, passed in 2000, set the minimum percentages of budget resources that the Federal, State, and Municipal governments are required to spend on public health. Taking a descriptive approach, this article aims to verify the compliance with Amendment 29 at various levels of government, from 2000 to 2003. Data were obtained from the Public Health System Budget Database (SIOPS). From 2000 to 2003, there was a cumulative deficit with the Unified National Health System (SUS) of R $\$ 1.8$ billion on the part of the Federal government and $R \$ 5.29$ billion by the States. In 2000, 59\% of the States complied with Amendment 29. In 2001, only 33\% complied. Some $41 \%$ reached the target in 2002 and 52\% in 2003. The SIOPS database showed that the average spending on health by Municipalities reached 13.67\%, 14.82\%, 16.54\%, and 17.4\% in 2000, 2001, 2002 and 2003, respectively.
\end{abstract}

Health Financing; National Health System (BR); Budgets
Magali Geovana Ramlow Campelli 1

Maria Cristina M. Calvo 1

\section{Introdução}

Uma nova forma de financiar o setor saúde se deu com a aprovação da Emenda Constitucional no. 29 (EC-29), de 13 de setembro de 2000, que estabeleceu as regras para a progressiva provisão de recursos às ações e serviços públicos de saúde. Antes, a única vinculação constitucional existente era para a área da Educação, com o percentual de $18 \%$ de receitas da União e $25 \%$ dos Estados e municípios.

A EC-29 determinou a vinculação e estabeleceu a base de cálculo e os percentuais mínimos de recursos orçamentários que a União, os Estados, Distrito Federal e municípios seriam obrigados a aplicar em ações e serviços públicos de saúde. Com as alterações propostas pela EC-29, destaca-se a nova redação dada ao artigo 198 da Constituição Federal tratando da base de cálculo. O parágrafo $3^{\circ}$ passou a prever a possibilidade de os percentuais mínimos serem reavaliados, em Lei Complementar, pelo menos a cada cinco anos, a contar da data da promulgação da Emenda. Da mesma forma, o artigo 77 do Ato das Disposições Constitucionais Transitórias (ADCT) estabeleceu os porcentuais mínimos naquela ocasião.

A EC-29, ou Emenda Constitucional da Saúde, foi criada com o objetivo de evitar a repetição dos problemas que comprometeram o financiamento do Sistema Único de Saúde (SUS) nos anos 90. Nessa década não havia um parâmetro legal que obrigasse os Estados, Distrito Federal e municí- 
pios a destinarem recursos próprios para a área de saúde; a economia e as políticas públicas das fontes de financiamento no âmbito da União para financiar o SUS eram instáveis e sempre se adotavam medidas emergenciais e provisórias para fazer frente à falta de recursos para o setor 1 .

A EC-29 alterou os artigos 34, 35, 156, 160, 167 e 198 da Constituição Federal e acrescentou um artigo ao ADCT, para assegurar os recursos mínimos para o financiamento das ações e serviços públicos de saúde 2 .

Rezende 3 destaca as alterações aprovadas:

- No artigo 34 da Constituição Federal, além da Educação, incluiu-se também a Saúde com a vinculação de percentuais mínimos para a aplicação destas ações;

- No artigo 35, inciso III, o Estado e a União são autorizados a intervir nos municípios nos casos de não aplicação do mínimo;

- O artigo 156, $\S 1^{\circ}$, estabelece a progressividade do Imposto Predial e Territorial Urbano (IPTU); além da "progressividade no tempo", também estabelece progressividade em razão do "valor do imóvel”. Desse modo, cada município poderá elaborar a sua Lei Municipal que trata do IPTU, incluindo a progressividade em relação ao valor, à localização e uso do imóvel;

- O artigo 160, parágrafo único, incisos I e II, veda à União reter ou promover restrição à entrega dos recursos atribuídos ao sistema de saúde;

- O artigo 167, inciso IV, ressalva a vinculação de receitas de impostos para a destinação de recursos para as ações e serviços públicos de saúde;

- O artigo 198, $\$ \$ 2^{\circ}$ e $3^{\circ}$, estabelece a aplicação, anual, de recursos mínimos em ações e serviços públicos de saúde.

As diretrizes sobre a aplicação da EC-29 foram aprovadas no Conselho Nacional de Saúde (CNS) pela Resolução $n^{\circ}$. 322, de 8 de maio de 2003. Os cálculos nessa resolução representam os percentuais mínimos a serem aplicados pelos Estados e municípios durante a regra de transição, de 2000 a 2004, para permitir os ajustes graduais nos orçamentos. A partir do ano de 2005, caso não seja aprovada a Lei Complementar, prevalecerão os percentuais de 2004 para Estados, Distrito Federal e municípios e a variação nominal do Produto Interno Bruto (PIB) para a União (Tabela 1).

À União foi determinado um acréscimo de 5\% em 2000 em relação ao valor empenhado no ano anterior (ADCT, artigo 77, I, “a”) e para os anos de 2001 a 2004, o valor apurado no ano anterior, corrigido pela variação nominal do PIB (ADCT, artigo 77, I, “b”). A definição dos critérios de vinculação da União após 2005 ficou ao encargo da Lei Complementar (Constituição Federal, artigo $\left.198, \S 2^{\circ}, \mathrm{c} / \mathrm{c} \S 3^{\circ}, \mathrm{IV}\right)$.
Tabela 1

Percentuais mínimos de vinculação orçamentária para o Sistema Único de Saúde (SUS), conforme o ano e nível de governo, nos termos da Emenda Constitucional no. 29.

\begin{tabular}{ccc}
\hline Ano & Estados & Municípios \\
\hline 2000 & 7,0 & 7,0 \\
2001 & 8,0 & 8,6 \\
2002 & 9,0 & 10,2 \\
2003 & 10,0 & 11,8 \\
2004 & 12,0 & 15,0 \\
\hline
\end{tabular}

Fonte: Resolução no. 322/2003 do Conselho Nacional de Saúde.

O Distrito Federal tem como base vinculável os percentuais equivalentes aos dos Estados sobre as receitas referidas no artigo 198, $\$ 2^{\circ}$, II e III, da Constituição Federal e no artigo 77, II; e percentuais equivalentes aos dos municípios sobre as fontes de recursos mencionadas no artigo 77, III, ambos do ADCT.

Para os Estados foi fixado, ao final de 2004, o limite mínimo de $12 \%$ do produto da arrecadação dos impostos sobre transmissão causa mortis e doação, operações relativas à circulação de mercadorias e sobre propriedade de veículos automotores (artigo 155 da Constituição Federal) e dos recursos provenientes de transferências da União de que tratam os artigos 157 e 159, inciso I, alínea a, e inciso II da Constituição Federal, deduzidas as parcelas que forem transferidas aos municípios.

Para os municípios, fixou-se, ao final de 2004, o percentual mínimo de $15 \%$ do produto da arrecadação dos impostos de propriedade predial e territorial urbana, transmissão "inter-vivos", a qualquer título, por ato oneroso, de bens imóveis, por natureza ou acessão física, e de direitos reais sobre imóveis e impostos sobre serviços de qualquer natureza (artigo 156) e dos recursos provenientes das transferências da União e dos Estados de que tratam os artigos 158 e 159, inciso I, alínea b e $\$ 3^{\circ}$. Para Estados e municípios, no ano 2000, os percentuais foram fixados a partir de um patamar de $7 \%$ da receita vinculável.

No ano 2000 nenhum Estado e município poderia aplicar menos do que $7 \%$ da receita vinculada. Para o período de 2001 a 2004, a diferença entre o efetivamente aplicado e os percentuais estipulados de $12 \%$ e $15 \%$ deverá ser reduzida na razão mínima de um quinto ao ano.

Na opinião de Mendes 4, o problema do financiamento da saúde continua "crônico". Prova disso é que, nas últimas reuniões do ano de 2004 
da Comissão de Orçamento e Finanças do Conselho Nacional de Saúde (COFIN/CNS) e da Câmara Técnica do Sistema de Informações sobre Orçamentos Públicos em Saúde (SIOPS), foram discutidos e analisados diversos aspectos que integram o campo do financiamento do SUS. Entre estes, destacam-se o descumprimento da EC-29 pelo Governo Federal e pelos governos estaduais e o estágio do Projeto de Lei Complementar no. 1/2003 (PLC 01/2003).

As definições legais dadas pela EC-29 constituem importante mecanismo de garantia dos recursos para a saúde. Assim, o cumprimento das exigências deve ser monitorado e avaliado para garantir tais recursos.

Este estudo tem o objetivo de verificar o cumprimento da EC-29 no Brasil no período de 2000 a 2003, analisando seu cumprimento pelos entes Federativos.

\section{Metodologia}

Este estudo é descritivo, sendo utilizados dados públicos, disponíveis no SIOPS. Esse sistema é uma referência para o acompanhamento, a fiscalização e o controle da aplicação dos recursos vinculados em ações e serviços públicos de saúde. São analisados os valores percentuais aplicados pelas diferentes esferas de governo e comparados aos valores mínimos previstos para o período de transição da EC-29. Os dados do ano de 2004 ainda não estavam publicados pelo SIOPS até a elaboração do artigo.

O SIOPS "é um sistema de coleta e processamento de dados sobre receitas totais e gastos com ações e serviços públicos de saúde das três esferas de governo" 5. As informações contidas no sistema são fornecidas e transmitidas pelas Secretarias Estaduais e Municipais de Saúde. O SIOPS dispõe de dados desde 1998 e seu preenchimento passou a ser semestral em 2002, facilitando o acompanhamento da programação e execução orçamentária na área de saúde.

\section{Resultados}

A União não vem cumprindo a EC-29 conforme a Constituição Federal, artigo 77 do ADCT, I, alínea "a”. A Tabela 2 mostra que a União deixou de aplicar em saúde um valor acumulado de R\$ 1,8 bilhão. O valor mínimo a ser aplicado está em conformidade com a segunda diretriz da Resolução $n^{o}$. 322/2003 do CNS, estabelecendo que a variação nominal do PIB seja aplicada sobre o montante empenhado no ano anterior, se igual ou superior ao mínimo estabelecido pela EC-29; caso contrário, a variação percentual do PIB deve ser aplicada sobre o valor mínimo.

Os dados do SIOPS revelam que também os Estados não vêm cumprindo a EC-29. A Tabela 3 indica que, no ano 2000, 11 Estados não cumpriram a EC-29, o que representou um passivo de $\mathrm{R} \$ 0,88$ bilhão. No ano de 2001, esse número aumentou para 18, e deixaram de ser aplicados em saúde R\$ 1,08 bilhão. Em 2002, foram 16 Estados, representando um passivo de $\mathrm{R} \$ 1,66 \mathrm{bi}$ lhão. Em 2003, 13 Estados deixaram de cumprir o mínimo exigido pela EC-29, o que representa a não aplicação de recursos financeiros na ordem de R\$ 1,67 bilhão. O déficit acumulado até 2003 representa uma dívida de $\mathrm{R} \$ 5,29$ bilhões com o SUS 6.

Valores mínimos definidos pela Emenda Constitucional no. 29.

\begin{tabular}{|c|c|c|c|c|}
\hline Ano & Valor mínimo a ser aplicado & Valor empenhado * & Variação do PIB (\%) & Déficit \\
\hline 2000 & 19.271 ** & 20.351 & & - \\
\hline 2001 & 23.013 & 22.474 & 13,083 & 539 \\
\hline 2002 & 25.050 & 24.736 & 8,852 & 314 \\
\hline 2003 & 28.128 & 27.181 & 12,287 & 947 \\
\hline Déficit acumulado & & & & 1.800 \\
\hline
\end{tabular}

Nota: em milhões de Reais nominais.

Fonte: Ministério da Saúde/Sistema Integrado de Administração Financeira/Sistema de Informações sobre Orçamento Público em Saúde/Instituto Brasileiro de Geografia e Estatística.

* Despesas empenhadas com Ações e Serviços Públicos de Saúde pelo Ministério da Saúde com a exclusão das despesas com inativos e pensionistas, dívidas e as do Fundo de Combate e Erradicação da Pobreza;

** Em 2000 acresceu-se 5\% sobre o valor de R\$18.353 milhões, empenhado pelo Ministério da Saúde em 1999 
Percentual de recurso próprio aplicado em saúde, conforme Emenda Constitucional no. 29 (EC-29), por Região, Unidade da Federação (UF) e período.

\begin{tabular}{|c|c|c|c|c|}
\hline Região/UF & 2000 & 2001 & 2002 & 2003 \\
\hline \multicolumn{5}{|l|}{ Norte } \\
\hline Acre & 19,11 & 14,80 & 13,89 & 12,96 \\
\hline Amapá & 17,96 & 21,30 & 27,80 & 25,63 \\
\hline Amazonas & 12,36 & 10,35 * & 12,53 & 10,56 \\
\hline Pará & 7,77 & 8,88 & 9,88 & 14,87 \\
\hline Rondônia & 7,84 & 10,64 & 9,67 & 10,43 \\
\hline Roraima & 11,39 & 14,20 & 10,14 * & 12,30 \\
\hline Tocantins & 8,12 & 12,30 & 11,48 & 11,32 \\
\hline Média & 12,08 & 13,21 & 13,63 & 14,01 \\
\hline \multicolumn{5}{|l|}{ Nordeste } \\
\hline Alagoas & 6,88 * & 7,96 * & 9,46 & 8,96 * \\
\hline Bahia & 8,32 & 8,83 * & 9,41 * & 10,61 \\
\hline Ceará & 9,69 & 7,51 * & 9,30 * & 9,38 * \\
\hline Maranhão & 1,52 * & 1,76 * & 5,51 * & 5,96 * \\
\hline Paraíba & 4,41 * & 12,82 & 11,29 & 7,83 * \\
\hline Pernambuco & 8,13 & 10,94 & 9,20 * & 9,80 * \\
\hline Piauí & 5,03 * & 7,11 * & 6,07 * & 7,35 * \\
\hline Rio Grande do Norte & 12,94 & 11,64 * & 13,30 & 14,15 \\
\hline Sergipe & 3,34 * & 5,80 * & 8,06 * & 10,07 \\
\hline Média & 6,70 & 8,26 & 9,07 & 9,35 \\
\hline \multicolumn{5}{|l|}{ Centro-Oeste } \\
\hline Distrito Federal & 9,74 & 8,91 * & 9,82 * & 11,17 * \\
\hline Goiás & 9,72 & 8,78 * & 7,71 * & 9,28 * \\
\hline Mato Grosso & 4,15 * & 6,81 * & 10,53 & 7,65 * \\
\hline Mato Grosso do Sul & 2,33 * & 6,33 * & 7,72 * & 9,49 * \\
\hline Média & 6,49 & 7,71 & 8,95 & 9,40 \\
\hline \multicolumn{5}{|l|}{ Sudeste } \\
\hline Espírito Santo & 10,37 & 9,38 * & 9,38 * & 12,43 \\
\hline Minas Gerais & 3,74 * & 6,91 * & 6,35 * & 10,20 \\
\hline Rio de Janeiro & 5,41 * & 5,05 * & 5,57 * & 8,04 * \\
\hline São Paulo & 7,80 & 8,94 & 10,74 & 12,26 \\
\hline Média & 6,83 & 7,57 & 8,01 & 10,73 \\
\hline \multicolumn{5}{|l|}{ Sul } \\
\hline Paraná & 2,48 * & 3,70 * & 4,52 * & 6,35 * \\
\hline Rio Grande do Sul & 6,60 * & 7,19 * & 5,14 * & 5,87 * \\
\hline Santa Catarina & 8,77 & 8,43 * & 7,48 * & 10,79 \\
\hline Média & 5,92 & 6,44 & 5,71 & 7,67 \\
\hline \multicolumn{5}{|l|}{ Brasil } \\
\hline Média & 7,99 & 9,16 & 9,70 & 10,58 \\
\hline
\end{tabular}

* Valores percentuais menores que as metas previstas na EC-29 para o período.

Comparando-se a média das Regiões, verifica-se que somente a Região Norte vem cumprindo regularmente os percentuais mínimos da EC-29. Contudo, é crescente o percentual médio de aplicação em ações e serviços de saúde no decorrer do período analisado.

Verifica-se que os Estados deixaram de aplicar $\mathrm{R} \$ 5,29$ bilhões no período, enquanto que a
União deixou de aplicar $\mathrm{R} \$ 1,8$ bilhão. Isso representa um montante de $\mathrm{R} \$ 7,09$ bilhões que $\mathrm{o}$ setor saúde deixou de receber nesses anos.

Pela regra de transição, os municípios deveriam alocar, em 2000, pelo menos $7 \%$ das receitas de impostos, compreendidas as transferências, devendo este percentual aumentar gradativamente até atingir 15\% em 2004. As informações 
existentes no SIOPS demonstram que a média percentual de recursos próprios aplicados em saúde pelo total dos municípios no ano 2000 foi de 13,67\%. Em 2001 foi de 14,82\%, aumentando para $16,54 \%$ em 2002 , e para $17,4 \%$ em 2003 ; ou seja, os percentuais são superiores aos mínimos recomendados pela Constituição Federal com a introdução da EC-29.

Em levantamento realizado em 1998 pelo Ministério da Saúde, em 1.500 municípios o percentual destinado à saúde foi de $15 \%$ das receitas de impostos e transferências constitucionais, indicando que, para os municípios, a vinculação de recursos não alterou o quadro do financiamento da saúde ?

Na Tabela 4 estão os percentuais de municípios que cumpriram a EC-29 em cada Estado, no período analisado. Os Estados da Região Norte apresentaram os maiores percentuais de municípios em situação irregular. Apenas Rondônia, em 2003, teve cumprimento da EC-29 por mais de $90 \%$ de seus municípios. Roraima, Amazonas, Tocantins e Amapá tiveram menos que $75 \%$ de seus municípios cumprindo a Emenda na maior parte do período analisado. Os Estados da Região Sudeste tiveram os maiores percentuais de municípios cumprindo a Emenda nesse período. $\mathrm{O}$ ano de 2001 foi o que apresentou menor número de municípios cumprindo a EC-29 em todos os Estados, com exceção de Roraima, que apresentou tendência decrescente de municípios cumprindo a Emenda em todo o período analisado, chegando a 18,18\% em 2003.

O PLC $01 / 2003$, previsto para a regulamentação da EC-29 no Congresso Nacional, foi aprovado em dezembro de 2004, por unanimidade pela Comissão da Seguridade Social e Família e pela Comissão de Finanças e Tributação da Câmara dos Deputados 8 .

O projeto define o conceito de ações e serviços de saúde, orienta a alocação, distribuição e controle dos recursos do SUS, de acordo com as necessidades de saúde da população e com os princípios e diretrizes da Universalidade, Eqüidade, Integralidade, Descentralização, Regionalização e Participação Social. Em abril de 2005, o projeto encontrava-se na Comissão de Constituição e Justiça e de Cidadania para ser votado. É importante destacar que esse projeto garante o aumento da contribuição da União, matéria de deliberação na 12a Conferência Nacional de Saúde, que aprovou a vinculação de $10 \%$ das receitas correntes brutas da União para a saúde. Isso representa uma aplicação um pouco maior, que o Governo Federal já atingiu em 1995, e muito menor que o previsto no ADCT da Constituição Federal - "o mínimo de 30\% do Orçamento da Seguridade Social, além dos recursos de impostos das três esferas de governo, caso fosse cumprido esse dispositivo Constitucional, não teriam ocorrido as graves crises na saúde nos anos 90" 9 .

Para Mendes 10, a aprovação do PLC 01/2003 torna-se imperativa para assegurar o direito social da saúde, sobretudo em uma sociedade com tantas desigualdades como a brasileira. Tal regulamentação "visa propiciar segurança jurídica contra quaisquer arranjos que tornem o direito à saúde vítima dos ajustes orçamentários, como daqueles praticados em governos sem compromisso com o direito à cidadania" 10.

Por sua vez, Rezende 3 considera que a EC-29, a Constituição Federal, as Leis Orgânicas da Saúde e a Lei $n^{o}$. 4.320/64 são claras no que tange às responsabilidades e às atribuições dos entes federativos quanto ao financiamento do SUS e à forma de viabilizá-lo. Caso a Lei Complementar não seja aprovada na época oportuna, a própria Emenda prevê que as atuais formas de financiamento não sofrerão mudanças.

A Tabela 5 mostra que após a EC-29 os gastos públicos apresentam uma tendência crescente nas aplicações dos recursos em saúde. A despesa por habitante, que era de $\mathrm{R} \$ 201,20$ em 2000, aumentou para $\mathrm{R} \$ 304,18 \mathrm{em} 2003$. Isso representou um incremento do PIB, em termos percentuais, de 3,09\% em 2000 para 3,45\% em 2003.

Segundo os dados do SIOPS, o Brasil investiu em 2003 R\$ 56,6 bilhões em ações de saúde. Destes, R\$27,2 bilhões foram recursos da União, representando $48 \%$ do total de recursos aplicados. A União vem reduzindo sua participação relativa no financiamento da saúde após a EC-29. Em 2000 sua participação era de 59,8\%; em 2001 de 56,2\%, em 2002 de 53,1\% e em 2003 de $48 \%$. Constata-se que, se de um lado há uma diminuição da participação da União, por outro, há o conseqüente aumento relativo dos gastos em saúde para os Estados e municípios.

\section{Discussão}

Para Marques \& Mendes 7, a aprovação da EC-29 levou a que muitos festejassem o início de um período próspero de recursos para o SUS. Entretanto, segundo os autores, a EC-29 "não chega a resolver o problema da insuficiência de recursos da área e tampouco sua relação com as diversas fontes da Seguridade" 7. A EC-29 introduziu uma inovação ao vincular recursos para o financiamento da saúde, pois define o quanto das receitas resultantes de impostos e transferências constitucionais dos Estados e municípios deve ser destinado para a área. Quanto à União, não ficou explícita a origem dos recursos, ficando fixado que, do total empenhado em ações e servi- 
Percentual de municípios que cumpriram a Emenda Constitucional no. 29, segundo Região, Unidade da Federação (UF) e período.

\begin{tabular}{|c|c|c|c|c|}
\hline Região/UF & 2000 & 2001 & 2002 & 2003 \\
\hline \multicolumn{5}{|l|}{ Norte } \\
\hline Acre & 61,90 & 54,55 & 81,82 & 80,95 \\
\hline Amapá & 57,14 & 38,46 & 69,23 & 87,50 \\
\hline Amazonas & 83,64 & 61,82 & 58,00 & 72,41 \\
\hline Pará & 76,53 & 64,71 & 80,17 & 78,10 \\
\hline Rondônia & 88,37 & 78,57 & 85,00 & 96,97 \\
\hline Roraima & 50,00 & 46,15 & 23,08 & 18,18 \\
\hline Tocantins & 73,95 & 55,56 & 67,57 & 80,00 \\
\hline Média & 76,06 & 60,89 & 71,51 & 78,50 \\
\hline \multicolumn{5}{|l|}{ Nordeste } \\
\hline Alagoas & 81,72 & 65,63 & 81,05 & 85,06 \\
\hline Bahia & 78,01 & 62,22 & 78,77 & 86,36 \\
\hline Ceará & 80,33 & 77,72 & 80,98 & 87,50 \\
\hline Maranhão & 82,14 & 66,67 & 75,74 & 83,64 \\
\hline Paraíba & 79,19 & 65,28 & 69,27 & 82,84 \\
\hline Pernambuco & 77,53 & 72,51 & 75,76 & 92,67 \\
\hline Piauí & 75,84 & 51,96 & 63,33 & 71,90 \\
\hline Rio Grande do Norte & 92,62 & 79,47 & 82,35 & 90,37 \\
\hline Sergipe & 71,62 & 66,67 & 76,00 & 81,33 \\
\hline Média & 79,78 & 66,75 & 75,84 & 85,06 \\
\hline \multicolumn{5}{|l|}{ Centro-Oeste } \\
\hline Goiás & 75,11 & 53,85 & 68,64 & 75,62 \\
\hline Mato Grosso & 91,13 & 67,39 & 81,16 & 88,46 \\
\hline Mato Grosso do Sul & 79,22 & 61,04 & 76,62 & 87,67 \\
\hline Média & 80,41 & 59,24 & 74,02 & 81,93 \\
\hline \multicolumn{5}{|l|}{ Sudeste } \\
\hline Espírito Santo & 79,22 & 69,23 & 91,03 & 81,69 \\
\hline Minas Gerais & 92,19 & 69,47 & 80,14 & 87,74 \\
\hline Rio de Janeiro & 93,10 & 81,82 & 90,12 & 95,24 \\
\hline São Paulo & 98,60 & 78,73 & 91,94 & 97,20 \\
\hline Média & 94,14 & 73,72 & 85,76 & 91,56 \\
\hline \multicolumn{5}{|l|}{ Sul } \\
\hline Paraná & 91,62 & 52,77 & 74,13 & 90,00 \\
\hline Rio Grande do Sul & 86,94 & 55,33 & 68,01 & 74,85 \\
\hline Santa Catarina & 84,30 & 59,04 & 73,38 & 86,69 \\
\hline Média & 87,83 & 55,43 & 71,33 & 82,54 \\
\hline Brasil & 85,92 & 65,36 & 77,52 & 85,93 \\
\hline
\end{tabular}

Fonte: Sistema de Informações sobre Orçamento Público em Saúde.

ços de saúde no ano anterior, acrescentar-se-ia a variação nominal do PIB para o ano seguinte. Os autores reconhecem que, considerando que a maioria dos Estados vinha destinando apenas $6 \%$ de suas receitas de impostos e transferências constitucionais para saúde, a EC-29 realmente ampliou esta participação no financiamento da saúde. Contudo, apesar de ser observado um aumento nos percentuais de recursos próprios para a saúde, nos estados o descumprimento da
EC-29 vem sendo constante. Merece enfatizar o fato de algumas unidades federadas não terem cumprido a EC-29 em todos esses anos 7.

A situação dos municípios foi menos alterada com a implantação da EC-29, pois em 2000 a média percentual de aplicação em ações de saúde já era superior ao mínimo constitucional de $7 \%$ ao ano. O número de municípios que cumprem as metas da Emenda não sofreu aumento significativo entre 2000 e 2003, observando-se que nos 
Gastos com saúde financiados com recursos próprios e em relação ao percentual do PIB.

\begin{tabular}{|c|c|c|c|c|c|c|c|c|}
\hline \multirow[t]{2}{*}{ Ano } & \multicolumn{2}{|c|}{ União } & \multicolumn{2}{|c|}{ Estados } & \multicolumn{2}{|c|}{ Municípios } & \multicolumn{2}{|c|}{ Total } \\
\hline & $\mathrm{R} \$$ * & $\%$ PIB & $\mathrm{R} \$$ * & $\%$ PIB & $\mathrm{R} \$$ * & $\%$ PIB & $\mathrm{R} \$$ * & $\%$ PIB \\
\hline 2000 & 20.351 & 1,85 & 6.313 & 0,57 & 7.404 & 0,67 & 34.069 & 3,09 \\
\hline 2001 & 22.474 & 1,87 & 8.270 & 0,69 & 9.269 & 0,77 & 40.013 & 3,33 \\
\hline 2002 & 24.737 & 1,87 & 10.309 & 0,76 & 11.759 & 0,89 & 46.805 & 3,52 \\
\hline 2003 & 27.181 & 1,75 & 12.224 & 0,79 & 14.219 & 0,91 & 56.624 & 3,45 \\
\hline
\end{tabular}

* Milhões de Reais correntes.

Fonte: Notas técnicas 10/2004 e 09/2005 (Sistema de Informações sobre Orçamento Público em Saúde).

anos 2001 e 2002 houve uma queda nesse número em relação ao início do período.

Segundo entendimento do Conselho Nacional de Secretarias Municipais de Saúde (CONASEMS), o que se vê é um embate entre a União, os Estados e a Constituição Federal no que tange ao volume de recursos aplicados destes entes no financiamento da saúde. Quanto aos municípios, pelos dados apontados no SIOPS, a maioria já apresentava percentual de aplicação em ações de saúde superior ao mínimo constitucional de 7\% ao ano na implantação da EC-29 em 2000. Por se tratar de matéria constitucional, garantida pela Carta Magna como um direito fundamental, a questão da saúde não pode ficar sujeita às disputas e divergências entre esferas da administração pública, cabendo ao Ministério Público zelar pela sua proteção, conforme atribuição que lhe é concedida pelos artigos 127 e 129 da Constituição Federal.

Apesar de já existirem parâmetros claros e acordados entre o Ministério da Saúde, os Estados e seus Tribunais de Contas sobre o que seria incluído como despesas de ações e serviços de saúde, nos termos da Portaria no. 2047/2002/GM e Resolução $n^{\circ}$. 322/03 do CNS, cabe salientar que dentre os Estados que indicaram o cumprimento da EC-29 nos anos mencionados, alguns incluíram gastos considerados alheios à saúde, tais como as despesas com inativos, com saneamento, habitação urbana, recursos hídricos, merenda escolar, programas de alimentação e hospitais de clientela fechada, para atingirem as metas de aplicação. É importante que o conteúdo das despesas com ações e serviços de saúde incluído em cada Estado seja verificado e avaliado a partir de um padrão comum para o conjunto dos entes federados 11 .

Igual raciocínio se aplica nos casos de despesas com a dívida pública e precatórios. É interessante ressaltar que as "ações e serviços públicos de saúde não podem ser confundidos de forma oportunista com todas as outras ações e serviços públicos, próprios de outros setores, que promovam a qualidade de vida e saúde da população" 3.

Também o Governo Federal está sujeito a distintas interpretações, a depender da posição adotada em relação aos dois principais dissensos: a definição sobre quais gastos podem ser considerados como ações e serviços públicos de saúde; e a base de cálculo a ser utilizada para a previsão mínima de recursos, que consiste na contraposição entre os critérios de "base móvel" e "base fixa". Para a União, em 2000, o montante mínimo aplicado em ações de saúde deveria ser o valor empenhado em 1999 acrescido de 5\%. Nos anos seguintes, entre 2001 e 2004, o valor apurado no ano anterior corrigido pela variação nominal do PIB.

Pelas interpretações "base fixa" versus "base móvel” pode-se concluir tanto pelo cumprimento da EC-29 quanto pelo seu desrespeito por parte do Governo Federal. A primeira interpretação, denominada como "base fixa", defende que o percentual de variação do PIB nominal é aplicado sobre o valor mínimo de recursos calculado para o ano anterior. Tal entendimento é defendido, fundamentalmente, pelo Ministério da Fazenda, pela Advocacia Geral da União e pelo Ministério do Planejamento, Orçamento e Gestão. A segunda interpretação, denominada como "base móvel”, defende que o termo "apurado" deve ser entendido como "empenhado", à semelhança do que foi definido pela EC-29 para o ano 2000. Essa interpretação é compartilhada pelo Ministério da Saúde, pelo CNS e pelo Tribunal de Contas da União (TCU), entre outros. Sob o enfoque de "base móvel", o percentual de variação do PIB nominal é aplicado sobre o volume de recursos executado no ano anterior, exceto quando este for inferior ao piso mínimo calculado. Pode-se ver que as distintas interpretações da EC-29 con- 
fundem o acompanhamento e a avaliação acerca do cumprimento desta. Na União, de acordo com o critério de "base fixa", vê-se que a EC-29 teria sido cumprida, excetuando o exercício de 2003. Contudo, se o critério utilizado fosse o de "base móvel”, a União teria cumprido a EC-29 apenas em 2000. Merece fazer menção ao Acórdão $n^{\circ}$. 957/2005 do TCU, de 13 de julho, que reafirma que o método considerado correto a ser adotado pela União, exigido pela EC-29, é o chamado critério de "base móvel" e que os gastos realizados por meio do Fundo de Combate e Erradicação da Pobreza, bem como os gastos do Programa Bolsa-Família, não devem ser considerados parte integrante dos recursos aplicados em Ações e Serviços Públicos em Saúde. Além disso, a Resolução $n^{\circ}$. 322 do CNS também não reconhece a natureza desses gastos para o cumprimento da EC-29 12,13.

Carvalho 14 salienta que a saúde pública expandiu-se claramente no período pós-constitucional, crescendo em quantidade e qualidade, e incluiu milhões de brasileiros na atenção básica e especializada. O fim da vinculação orçamentária de recursos representaria uma considerável diminuição de aportes financeiros para a saúde. Além disso, o conceito de ações de saúde ser ampliado significa que a saúde não terá mais dinheiro, mas mais obrigações a serem pagas com os mesmos recursos disponíveis.

Em defesa do PLC, quatro entidades ligadas à reforma sanitária brasileira (Centro Brasileiro de Estudos de Saúde - CEBES, Associação Brasileira dePós-Graduação em Saúde Coletiva-ABRASCO, Rede Unida e Associação Brasileira de Economia da Saúde - ABRES) divulgaram em 31 de agosto de 2004 manifesto sobre a necessidade da votação urgente do PLC 01/2003, que regulamenta a EC-29 9.

Um argumento central dessas organizações comprometidas com a saúde como direito fundamental é que a vinculação orçamentária visa ao comprometimento de financiamento estável, e possibilita o planejamento dos gastos e a prevenção de crises e insolvências, em nome da preservação da saúde e da vida de muitos milhões de pessoas. O desfinanciamento do SUS, por outro lado, é apontado como causa direta que impede a efetivação do novo modelo de atenção e gestão à saúde.

Embora a Resolução $n^{o} .322$ do CNS tenha procurado dirimir dúvidas quanto à interpretação da EC-29, por se tratar de ato administrativo, não tem força de Lei 15. De outro lado, há entendimento de que a EC-29 é auto-aplicável e suas exigências e efeitos são imediatos, não necessitando de nenhum instrumento legal para seu cumprimento 16 .
Entretanto, a 11ạ Conferência Nacional de Saúde 17 propugnou a aprovação de mecanismo legal que impusesse sanções pelo não cumprimento da EC-29, o que ocorrerá a partir do momento em que o parlamento brasileiro aprove o PLC 01/2003, que capitula como crime de responsabilidade o não cumprimento da EC-29, sujeitando o ente infrator às penalidades já existentes na LC no. 101 (Lei de Responsabilidade Fiscal), tais como a intervenção federal, o impedimento para receber transferências voluntárias, o impedimento para obter garantia de outro ente e para contratar operações de crédito 18.

A urgência da tramitação e aprovação do PLC 01/2003 foi reiterada nas recentes conferências nacionais de Ciência e Tecnologia em Saúde e de Saúde Bucal, em torno do substitutivo aprovado na Comissão de Seguridade Social e Família, e já encaminhado à Comissão de Finanças e Tributação da Câmara dos Deputados.

O PLC 01/2003, contempla também todas as postulações aprovadas na 12a Conferência Nacional de Saúde, na Plenária Nacional de Conselheiros de Saúde e no Conselho Nacional de Saúde, em especial, a Resolução $n^{\circ}$. 322/03.

Por fim, esse projeto não só garante o compromisso da União, expresso em $10 \%$ da Receita Corrente Bruta, como também orienta a alocação, distribuição e controle dos recursos do SUS, estritamente de acordo com as necessidades de saúde da população e com os princípios e diretrizes da Universalidade, Eqüidade, Integralidade, Descentralização, Regionalização e Participação Social 9 .

Por outro lado, vê-se que os Tribunais de Contas, ao apreciarem as contas dos entes das três esferas, e diante da constatação de que tais entes não cumprem os limites estabelecidos na EC-29, apontam tais irregularidades como restrições, sem que haja uma efetiva punição. $\mathrm{O}$ Ministério Público, por sua vez, ao que se tem conhecimento, não age no sentido de fiscal da lei, promovendo a efetiva representação ao Judiciário no sentido de penalizar o agente público pela irregularidade indicada nos processos de apreciação de contas.

Para finalizar a abordagem sobre os aspectos que envolvem a efetiva aplicação da EC-29, torna-se necessário fazer uma referência do papel a ser desempenhado pelo controle social na efetivação deste disposto constitucional, que é, apesar de todas as dificuldades, o melhor caminho para a consolidação do SUS.

As considerações de Rezende 3 também apontam para essa direção, ao destacar que é necessário "apostar na capacidade de organização dos Conselheiros de Saúde das três esferas de gestão do SUS", investindo na capacitação de seus agen- 
tes, criando redes de informações e de troca de experiências. Tais iniciativas são determinantes para que "os recursos mínimos para a saúde previstos na EC-29 sejam realmente assegurados nas leis orçamentárias, para que sejam empenhados em tempo hábil, sem contingenciamentos e sejam executados. Os Conselhos de Saúde têm agora referência de valores financeiros para aprovarem ou não as prestações de contas do SUS" 3.

A vigilância dos Tribunais de Contas e do Ministério Público, na averiguação do desempenho e do comportamento governamental, como por exemplo, aquele que obriga a prestação trimestral de contas ao poder legislativo e a atuação dos Conselhos de Saúde, podem configurar um Controle Social mais efetivo.

\section{Conclusão}

Foram avaliadas as Unidades Federativas do Brasil no período de 2000 a 2003. O estudo verificou a evolução dos percentuais mínimos propostos pela EC-29. Observou-se em 2000 que 59\% dos estados atingiram as metas: sete no Norte, quatro no Nordeste, dois no Sudeste, um no Sul, e dois no Centro-Oeste. Em 2001 houve redução para $33 \%$ dos Estados no cumprimento das metas: seis do Norte, dois no Nordeste e um no Sudeste. Em 2002, 41\% dos Estados alcançaram as metas: seis no Norte, três no Nordeste, um no Sudeste, e um no Centro-Oeste. Em 2003, 52\% dos Estados atingiram as metas: sete no Norte, três no Nordeste, três no Sudeste e um no Sul. Essa análise permitiu constatar que a maioria dos Estados brasileiros ainda não cumpria os percentuais mínimos previstos na EC-29 no período analisado. Os Estados deixaram de aplicar R \$ 5,29 bilhões no período, e a União deixou de aplicar R\$ 1,8 bilhão, o que representa um montante de $\mathrm{R} \$ 7,09$ bilhões que o setor saúde deixou de receber nos quatro anos.

De acordo com o manual básico de Gestão Financeira do SUS, elaborado pelo Ministério da Saúde e Fundo Nacional de Saúde, "os Estados, o Distrito Federal e os Municípios que não cumprirem os limites mínimos fixados na CF/88 estarão sujeitos às mesmas sanções da Lei de Responsabilidade Fiscal (LRF) que vão desde retenção das transferências do Fundo de Participação dos Estados (FPE) e dos Municípios (FPM), até a intervenção da União, além da cassação de mandatos" 19. O que se constata é que essas penalidades não vêm sendo aplicadas aos entes que não estão cumprindo a EC-29.

A participação relativa da União, na composição dos gastos públicos em saúde, vem reduzindo gradativamente. Em 2003, esse percentual ficou abaixo de $50 \%$, invertendo toda a composição do financiamento. Mais responsabilidades e aportes financeiros ficaram sob a égide dos Estados e municípios.

Diante dos dados coletados, percebe-se a necessidade de que a vinculação constitucional de receita orçamentária dos entes federativos brasileiros para gastos obrigatórios em ações e serviços de saúde seja não só mantida, mas urgentemente regulamentada, pois ela significa a garantia material do direito à saúde, como definiu o CONASEMS 11.

Destaque-se que a EC-29 assegura apenas os recursos mínimos, cabendo aos gestores públicos aperfeiçoarem as leis orçamentárias. Há de se ter vontade política para efetivamente priorizar a saúde, pois a necessidade de mais recursos financeiros para o setor saúde no Brasil já está comprovada atualmente.

Na União, os orçamentos devem ser reavaliados periodicamente, em função de que o PIB somente é divulgado no ano seguinte ao da lei orçamentária aprovada. Não obstante, Estados e municípios devem acompanhar a evolução das receitas provenientes dos impostos vinculados à base de cálculo para apuração do valor a ser aplicado em saúde, em conformidade com os artigos da Constituição Federal. Tais acompanhamentos permitem realizar revisões para os ajustes orçamentários, promovendo assim viabilidade de cumprimento da EC-29.

O debate, mais uma vez, está aberto. As divergências, entretanto, não devem servir para distanciar, mas para produzir o consenso entre todos aqueles que propugnam pelo fortalecimento do SUS. 


\section{Resumo}

A aprovação da Emenda Constitucional no. 29 (EC-29) em 2000 determinou a vinculação de percentuais mínimos de recursos orçamentários que a União, Estados, Distrito Federal e municípios seriam obrigados a aplicar em ações e serviços públicos de saúde. O objetivo deste artigo é verificar o cumprimento da EC-29 no Brasil no período de 2000 a 2003. O estudo é descritivo utilizandose dados disponíveis no Sistema de Informações sobre Orçamentos Públicos em Saúde (SIOPS). Apresenta como resultado uma divida acumulada com o Sistema Único de Saúde de $R \$ 1,8$ bilhão na União e de R\$ 5,29 bilhões nos Estados. O total de Estados que cumpriram a EC-29 foi de 59\% em 2000, 33\% em 2001, 41\% em 2002 e $52 \%$ em 2003. Os dados do SIOPS mostraram que a média percentual de aplicação de recursos próprios municipais em ações e serviços de saúde era superior ao mínimo exigido de $7 \%$ previsto na Constituição Federal. A média percentual de recursos próprios aplicados pelos municípios ficou em 13,67\% em 2000, 14,82\% em 2001, 16,54\% em 2002 e 17,40\% em 2003

Financiamento em Saúde; Sistema Único de Saúde; Orçamentos

\section{Colaboradores}

M. G. R. Campelli participou de todas as etapas do estudo, sendo responsável pela coleta de dados do banco SIOPS, análise, interpretação e elaboração dos resultados da pesquisa. M. C. M. Calvo foi responsável pela orientação geral do artigo e pela revisão final, e participou na elaboração das tabelas e análise dos resultados.

\section{Referências}

1. Conselho Nacional de Secretários de Saúde. Para entender a gestão do SUS. Brasília: Conselho Nacional de Secretários de Saúde; 2003.

2. Brasil. Constituição da República Federativa: 1988 - texto constitucional de 5 de outubro de 1988 com as alterações adotadas pelas Emendas Constitucionais de $\mathrm{n}^{\circ}$. 1 , de 1992, a 32, de 2002 e pelas Emendas Constitucionais de Revisão nos. 1 a 6 de 1994. Brasília: Coordenação de Publicações, Câmara dos Deputados; 2001.

3. Rezende C. Nota técnica: a implementação da Emenda Constitucional 29 (Emenda da Saúde). http://www.pt.org.br (acessado em 18/Mar/2005).

4. Mendes Á. Um pouco de estória do financiamento na saúde. http://www.conasems.org.br (acessado em 18/Mar/2005).

5. Sistema de Informações sobre Orçamentos Públicos em Saúde. Afinal, o que é o SIOPS? http:// siops.datasus.gov.br (acessado em 18/Mar/2005).

6. Sistema de Informações sobre Orçamentos Públicos em Saúde. Nota técnica: SIOPS 009/2005. http://siops.datasus.gov.br (acessado em 15/ Set/2005).
7. Marques RM, Mendes A. Novas incertezas sobre o financiamento da saúde. Gazeta Mercantil 2000; 13 set.

8. Conselho Nacional de Secretários de Saúde. Nota técnica 29/2004 do CONASS. Anexo 5. Projeto de Lei Complementar $n^{\circ}$. 1, de 2003. http://www. conass.com.br (acessado em 10/Out/2005).

9. Centro Brasileiro de Estudos de Saúde/Associação Brasileira de Pós-Graduação em Saúde Coletiva/ Rede Unida/Associação Brasileira de Economia da Saúde. Reflexões atualizadas sobre a urgência da tramitação do Projeto de Lei Complementar da EC-29. Radis 2004; 27. http://www.ensp.fiocruz.br/ radis/27-web-01.html (acessado 19/Mar/2005).

10. Mendes A. O financiamento da saúde que se mostra por dentro e se esconde por fora. http://www. conasems.org.br (acessado em 28/Mar/2005).

11. Conselho Nacional de Secretários Municipais de Saúde. Parâmetros consensuais sobre a implementação e regulamentação da Emenda Constitucional 29. http://www.conasems.org.br (acessado em 17/Mar/2005). 
12. Ministério do Planejamento, Orçamento e Gestão. Boletim de políticas sociais: acompanhamento e análise, $\mathrm{n}^{\circ}$. 10. http://www.ipea.gov.br/ sites/000/2/publicacoes/bps_10.pdf (acessado em 13/Nov/2006)

13. Ministério do Planejamento, Orçamento e Gestão. Boletim de políticas sociais: acompanhamento e análise, $\mathrm{n}^{\circ}$. 11. http://www.ipea.gov.br/ sites/000/2/publicacoes/bps11.pdf (acessado em 13/Nov/2006).

14. Carvalho G. O governo do PT e a desvinculação dos recursos da saúde e educação. http://www. conasems.org.br (acessado em 18/Mar/2005).

15. Conselho Nacional de Saúde. Informativo eletrônico do CNS 2006; Ano III, no ${ }^{\circ}$ 12. http://conselho. saude.gov.br/biblioteca/Informativo/12.pdf (acessado em 13/Nov/2006).
16. Banco do Brasil. Transferências constitucionais da saúde. http://www.bb.com.br/appbb/portal/gov/ ep/srv/TransfConstitucionaisSaude.jsp (acessado em 13/Nov/2006).

17. Departamento de Informática do SUS. Financiamento da atenção à saúde no Brasil. http://www. datasus.gov.br/cns/11Conferencia/relatorio/ FINANCIAMENTO\%20DA\%20ATENCAO.htm (acessado em 17/Nov/2006).

18. Comissão de Constituição e Justiça e de Cidadania, Câmara dos Deputados. Projeto de Lei Complementar $n^{\circ}$. 1, de 2003. http://www.camara.gov. br/sileg/integras/274381.pdf (acessado em 17/ Nov/2006).

19. Fundo Nacional de Saúde, Ministério da Saúde. Gestão financeira do Sistema Único de Saúde: manual básico. 3a Ed. Brasília: Ministério da Saúde; 2003.

Recebido em 15/Mar/2006

Versão final reapresentada em 24/Nov/2006

Aprovado em 29/Jan/2007 